\title{
DRUG INDUCED HYPOGLYCEMIC COMA IN A NONDIABETIC WITH CHRONIC LIVER DISEASE: A CASE REPORT OF DRUG DISPENSING ERROR
}

\author{
Krishna M. Baradol${ }^{1}$, Dharmesh A. Ladhad ${ }^{2}$
}

\section{HOW TO CITE THIS ARTICLE:}

Krishna M. Baradol, Dharmesh A. Ladhad. "Drug Induced Hypoglycemic Coma in a Nondiabetic with Chronic Liver Disease: A Case Report of Drug Dispensing Error". Journal of Evolution of Medical and Dental Sciences 2014; Vol. 3, Issue 39, August 28; Page: 9940-9943, D0I: 10.14260/jemds/2014/3288

ABSTRACT: Hypoglycemia is a common, potentially fatal, yet preventable problem. Drug-induced hypoglycemia remains the commonest cause of hypoglycemia. A 63 year old non-diabetic male, a known case of chronic liver disease, on regular medications, presented with unconsciousness, unresponsiveness since two hours. Immediate random blood sugar was $11 \mathrm{mg} / \mathrm{dl}$. On proper history and clinical examination, diagnosis of oral hypoglycemic agent induced hypoglycemic coma was made and immediately intravenous dextrose resuscitation was started. Patient regained consciousness after four hours and became fully oriented after 24 hours. Throughout his hospital course, strict and frequent glucose monitoring was done and dextrose infused accordingly. Patient remained hemodynamically stable throughout the hospital course. He was discharged from the hospital after 72 hours in an otherwise healthy condition. Drug induced hypoglycemia is now so relatively common that virtually every unconscious patient should be considered hypoglycemic until immediate estimation of the blood sugar level rules the condition in or out.

KEYWORDS: Drug induced hypoglycemia, hypoglycemic coma, nondiabetic, chronic liver disease, drug dispensing error.

INTRODUCTION: Hypoglycemia, a syndrome characterized by adrenergic and neuroglycopenic symptoms induced by an abnormal level of plasma glucose (glycemia $<50 \mathrm{mg} / \mathrm{dl}$ ), is a common, potentially fatal, yet preventable problem. ${ }^{11]}$ Drug-induced hypoglycemia remains the commonest cause. [2] Groups of drugs that may potentiate hypoglycemia in non-diabetics are: insulin, sulphonylureas, beta-blockers, salicylates etc. [3] The brain cannot store or synthesize glucose. Glucose depletion to the brain rapidly causes impaired neuronal function, manifested by cognitive impairment or depression of level of consciousness, exhibited as obtundation, stupor or coma. ${ }^{[1]}$

CASE HISTORY: A 63 year old non-diabetic male, known case of chronic liver disease since six years on regular medications, presented with abnormal behavior, sweating, staring at one point since four hours; unconsciousness, unresponsiveness since two hours. Since two days, the patient had been lethargic, excessively sleepy after taking some (supposed to be regular) tablets, so his wife promptly stopped giving those tablets to him. His food intake was adequate. The offending tablet was found to be Trivolib 1 (brand name), an oral hypoglycemic drug containing glimepiride $1 \mathrm{mg}$, voglibose $0.2 \mathrm{mg}$ and extended release metformin $500 \mathrm{mg}$. The patient being non-diabetic, had taken three tablets, each tablet 10 to 12 hours apart, last tablet he took was 36 hours back.

On clinical examination, the patient was unconscious, unresponsive, breathing spontaneously.

Vitals were stable. Glasgow coma score was 3/15. Pupils, mid dilated, reacting to light. Other systems were normal. Immediate capillary glucometer random blood sugar (GRBS) was $11 \mathrm{mg} / \mathrm{dl}$. Immediately resuscitation was started with $200 \mathrm{ml}$ of $25 \%$ dextrose (D) intravenously (IV) followed 
by $5 \% \mathrm{D}$ (75 ml/hour) infusion. The next four GRBS readings showed declining trend. So, 5\% D was replaced with $10 \% \mathrm{D}$ (50 ml/hour). After six hours, again the patient had severe hypoglycemia (GRBS $32 \mathrm{mg} / \mathrm{dl})$. So, 25\% D (20-40 ml/hour) was added along with 10\% D infusion. The readings are depicted in Graph 1.

The patient regained consciousness after four hours of meticulous IV dextrose resuscitation, but remained lethargic and disoriented for the next 18 to 20 hours. Patient became fully oriented after 24 hours. Strict, frequent and regular GRBS monitoring was done throughout the hospital course of the patient (Graph 1). The patient remained hemodynamically stable throughout. His laboratory investigations including liver function tests were normal. Oral feeds were started and IV dextrose was tapered down slowly. His routine medications were continued in the hospital. The patient was discharged from the hospital after 72 hours in an otherwise healthy euglycemic condition.

DISCUSSION: Oral hypoglycemic agents involved in drug induced hypoglycemic coma (DIHC) are: gliclazide, glibenclamide, metformin, repaglinide, glimepiride and buformin. ${ }^{[1]}$ Life-threatening hypoglycemia may develop in sulphonylurea-naive non-diabetics after ingestion of a single therapeutic dose. The duration of hypoglycemia may range from 12 to 24 hours or even longer in cases of large overdose, extended-release preparations as in this case, or long-acting preparations.

Prolonged hypoglycemia may also be observed when a relatively low dose of sulphonylurea is taken by patients with advanced age, or with impaired renal or hepatic function as in this case. In general, the hypoglycemic effect of metformin will only be seen in diabetics unless one simultaneously ingests another hypoglycemic agent or if he has co-existing severe hepatic insufficiency as seen in this case. [4]

Only $4 \%$ of the studies reported drug-induced hypoglycemia as a result of overdose, whereas majority of the studies (96\%) reported dosing consistent with standard clinical practice as in present case and hypoglycemia episodes were usually symptomatic and severe as seen in this case.[5] In one study, out of 473, 220 cases of hypoglycemic coma were caused by sulphonylureas and 28 by simultaneous administration of two hypoglycemic agents.[6] In this case, the patient had taken a triple combination of hypoglycemic agents. Overall the factors which led to hypoglycemic coma in present case are: old age, hepatic insufficiency and potent dose of hypoglycemic drugs.

Most sulphonylureas are metabolized in the liver. Therefore, in liver diseases the inactivation of the drugs is reduced, thereby prolonging their half-life. Hypoglycemic action is potentiated. [7] This could have contributed to coma in our patient. Liver function tests usually do not correlate well with the ability of liver to metabolize drugs. [7]

Patients may present with autonomic symptoms (e.g. sweating, hunger, paresthesia, tremor, palpitation and anxiety), neuroglycopenic symptoms (e.g. dizziness, weakness, confusion, drowsiness, seizure and coma), which may lead to death if unrecognized and untreated.[1] In a study of 79 cases of DIHC, all patients presented with unconsciousness, Glasgow Coma Score was below eight in all patients (range: three to seven) and blood glucose ranged from $12-52 \mathrm{mg} / \mathrm{dl}$ (mean $29.14 \mathrm{mg} / \mathrm{dl}$ ).[1]

All findings correlate with present case. Coma can occur at glucose levels in the range of 41$49 \mathrm{mg} / \mathrm{dl}$ as well as at lower glucose levels. [1]

Restricted food intake is a predisposing factor unlike in present case. Drug-induced 
hypoglycemia is now so relatively common that virtually every unconscious patient should be considered hypoglycemic until immediate estimation of the blood sugar level rules the condition in or out. If it is ruled in, the clinician should promptly start $10 \%$ glucose IV and plan to maintain it uninterruptedly for one or more days, with added hydrocortisone and glucagon if necessary, until persistent hyperglycemia guarantees that all drug effects have worn off; similarly we treated the patient with $10 \% \mathrm{D}$ and $25 \%$ D.[6]

Octreotide is safe and effective in preventing rebound hypoglycemia after sulphonylurea ingestion and in combination with glucose should be considered for first-line therapy in the treatment of sulphonylurea-induced hypoglycemia. [8] Treatment should not be withheld while waiting for a laboratory glucose value. Because the brain uses glucose as its primary energy source, neuronal damage may occur if treatment of hypoglycemia is delayed. [9] $97.47 \%$ patients recovered without sequelae following hypoglycemic coma as in our case. [1]

There have been cases of inadvertent dispensing or administration in which non-diabetics were given sulphonylureas. In most instances, confusion arose as a result of similarity in spelling and appearance between the intended medication and the sulphonylurea. [10] Presented case here was concluded as a case of drug dispensing error; the chemist dispensed the anti-diabetic drug instead of calcium tablet (similar looking tablet strips) which the patient had been taking regularly.

The antidiabetic drug was not at all indicated for this non-diabetic patient but wrongly dispensed by the pharmacist/chemist instead of calcium tablet which was one of the regular medications of the patient.

KEY MESSAGE: Physicians, pharmacy staff and other healthcare professionals should pay special attention to look-alike/sound-alike drugs (appearance, colourings, and spellings) to prevent prescribing, dispensing and administration errors.

\section{REFERENCES:}

1. Sorodoc L, Lionte C, Sorodoc V, Petris OR, Badiu C. Causes, morbidity and management of drug induced hypoglycemic coma in non-diabetic patients. Act Endocrinol 2009; 5: 337-48.

2. Ching CK, Lai CK, Poon WT, Lui MC, Lam YH, Shek CC, et al. Drug-induced hypoglycaemia - new insight into an old problem. Hong Kong Med J 2006; 12: 334-8.

3. Pytliak M, Vargova V, Mechirova V. Drugs and hypoglycemia. In: Rigobelo E, editor. Hypoglycemia - Causes and Occurrences. Shanghai: InTech; 2011. p. 131-48.

4. Woo M. Safety of oral antidiabetic drugs. Poisoning. Comm [Internet]. 2007 Jan [cited 2013 Aug 13]; 2(1): [p. 3-6]. Available from: http://www.poisoning.comm/2007/jan.

5. Murad MH, Coto-Yglesias F, Wang AT, Sheidaee N, Mullan RJ, Elamin MB, et al. Drug-induced hypoglycemia: A systematic review. J Clin Endocrinol Metab 2009; 94: 741-5.

6. Seltzer HS, Dallas MD. Drug-induced hypoglycemia: A review based on 473 cases. Diabetes 1972; 21: 955-66.

7. Saini JS. Management guidelines for use of oral hypoglycemic agents (OHA) in complex clinical situations and important drug interactions with OHA's. Intnl J Diab Dev Countries 1991; 11: 23-4. 


\section{CASE REPORT}

8. Fasano CJ, O'Malley G, Dominici P, Aguilera E, Latta DR. Comparison of octreotide and standard therapy versus standard therapy alone for the treatment of sulfonylurea-induced hypoglycemia. Ann Emerg Med 2008; 51: 400-6.

9. Lionte C, Sorodoc L, Laba V. Toxic-induced hypoglycemia in clinical practice. Rom J Intern Med 2004; 42: 447-55.

10. Richard AH, Michelle SN, Philip B. Oral agents for the treatment of type 2 diabetes mellitus: Pharmacology, toxicity and treatment. Ann Emer Med 2001; 38: 68-78.

\section{List of Abbreviations Used:}

GRBS - Glucometer random blood sugar.

D - Dextrose.

IV - Intravenous.

DIHC - Drug unduced hypoglycemic coma.

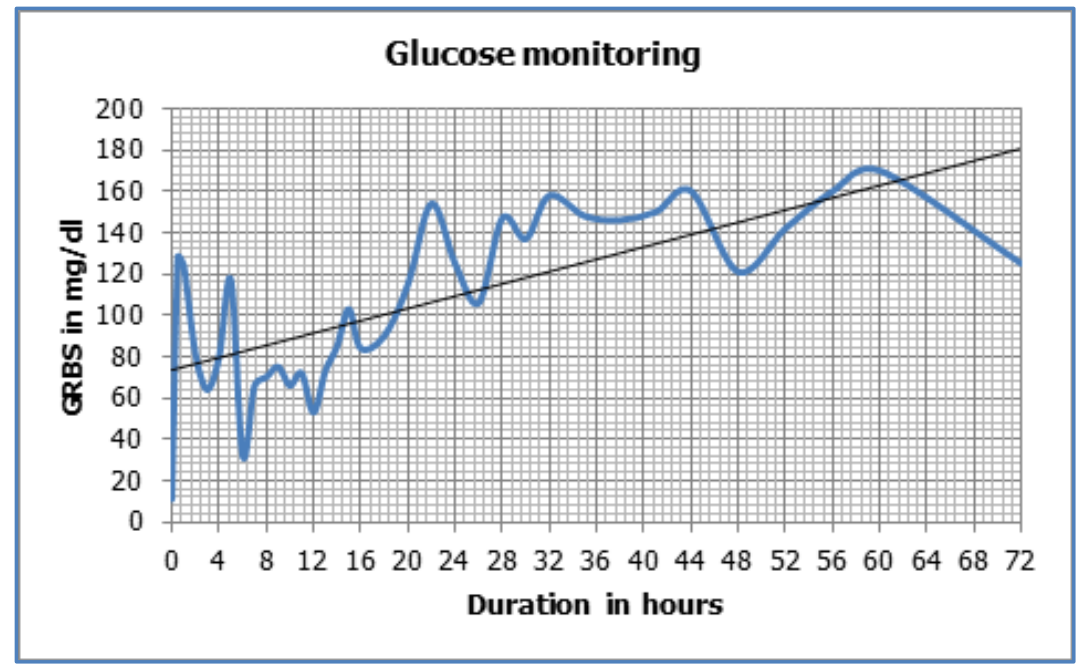

Graph 1: Glucose monitoring

*GRBS-Glucometer random blood sugar

\section{AUTHORS:}

1. Krishna M. Baradol

2. Dharmesh A. Ladhad

\section{PARTICULARS OF CONTRIBUTORS:}

1. Consultant Intensivist, Department Critical Care Medicine, Vaatsalya Hospital, IMZ Plaza, Dollars Colony, Gokul Road, Hubli, Karnataka.

2. Consultant Intensivist, Department Critical Care Medicine, Vaatsalya Hospital, IMZ Plaza, Dollars Colony, Gokul Road, Hubli, Karnataka.
NAME ADDRESS EMAIL ID OF THE CORRESPONDING AUTHOR:

Dr. Krishna Baradol,

12A, Laxmi Park, Sanman Colony,

Near Shree Mata Ashram,

Hubli-580024, Karnataka.

Email: drkrishbm@gmail.com

Date of Submission: 09/08/2014.

Date of Peer Review: 11/08/2014.

Date of Acceptance: 21/08/2014.

Date of Publishing: 27/08/2014. 